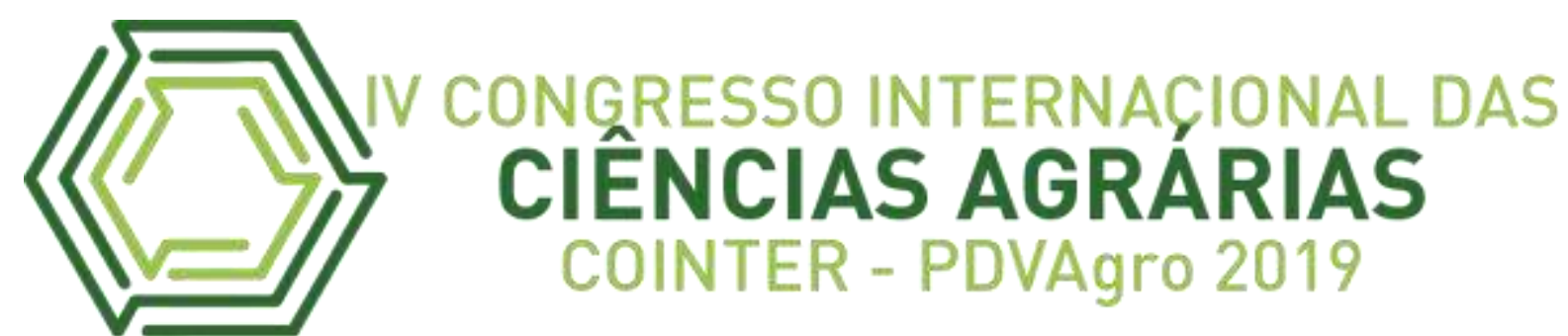

\title{
O COOPERATIVISMO E O DESAFIO DO DESENVOLVIMENTO ECONÔMICO LOCAL: reflexões a partir de alguns casos no Brasil
}

\section{COOPERATIVISMO Y EL DESAFÍO DEL DESARROLLO ECONÓMICO LOCAL: reflexiones de algunos casos en Brasil}

\section{COOPERATIVISM AND THE CHALLENGE OF LOCAL ECONOMIC DEVELOPMENT: reflections from some cases in Brazil}

\author{
Apresentação: Comunicação Oral \\ Edleuza Nere Brito de Souza1 ; Ingridi Antonia Matos de Souza²; Sidney Jorge Moreira Souza ${ }^{3}$;
} Ana Maria Machado Evangelista ${ }^{4}$; Paulo Protásio de Jesus ${ }^{5}$

DOI: $\underline{\text { https://doi.org/10.31692/2526-7701.IVCOINTERPDVAgro.2019.0017 }}$

\begin{abstract}
Resumo
As cooperativas caracterizam-se como agrupamentos de pessoas de forma organizada que necessitam de subscrição de capital para fortalecer as reservas e aumentar as receitas e assim contribuir para a emancipação dos seus cooperados, portanto, um modelo de organização social sustentado nos pilares econômico, social, político e cultural e contribui para a geração e distribuição de renda, de modo que fortalece a mobilização das energias sociais em espaços de pequena escala (municípios, localidades, microrregiões) que implementam mudanças capazes de elevar as oportunidades sociais, a viabilidade econômica e as condições de vida da população. Reconhecendo a importância destas organizações no contexto das transformações sociais e econômicas, o presente trabalho tem por objetivo refletir sobre três casos de cooperativas no Brasil, com resultados positivos quanto ao desenvolvimento econômico local. A pesquisa é do tipo qualitativa, sendo a investigação bibliográfica e documental o método utilizado. Os resultados evidenciam que todas as cooperativas analisadas, através da gestão democrática e trabalho em equipe, conseguiram crescer economicamente, gerando emprego e renda e atraindo investimentos e conquistas para sua região, entre esses, a construção de escolas comunitárias, desenvolvimento dos pequenos comércios, maiores índices de produtividade dos pequenos produtores através da comercialização de insumos, entre outros. Duas delas se tornaram referência na produção e comercialização de suas matéria-prima, uma outra obteve sucesso na atividade enquanto possuía um comprador certo para seu produto, falindo assim que este fechou as portas. Os resultados evidenciam ainda que o cooperativismo é uma importante ferramenta de desenvolvimento social, econômico e local, possuindo grande importância na geração de emprego e renda e contribuindo para o desenvolvimento da sociedade como um todo.
\end{abstract}

Palavras-Chave: cooperativismo, desenvolvimento econômico, desenvolvimento local, trabalho em equipe.

\footnotetext{
1 Professora Especialista do IFMA - Campus São Luís Maracanã; Mestranda do Programa de Pós-graduação em Cultura e Sociedade (PGCult) UFMA, pedagogaedleuza@gmail.com

${ }^{2}$ Aluna de Licenciatura em Ciências Agrárias, IFMA - Campus São Luís Maracanã, ingridi.antonia@gmail.com
} 
${ }^{3}$ Aluno de Licenciatura em Ciências Agrárias, IFMA - Campus São Luís Maracanã, sidneyjorge908@gmail.com

${ }^{4}$ Aluna do curso Técnico em Agropecuária, IFMA - Campus São Luís Maracanã, evangelistaa@acad.ifma.edu.br

${ }^{5}$ Aluno de Licenciatura em Ciências Agrárias, IFMA - Campus São Luís Maracanã, cerzar09@gmail.com

\title{
Resumen
}

Las cooperativas se caracterizan como grupos organizados de personas que necesitan una suscripción de capital para fortalecer las reservas y aumentar los ingresos y, por lo tanto, contribuir a la emancipación de sus miembros, por lo tanto, un modelo de organización social basado en lo económico, social y contribuye a la generación y distribución de ingresos, fortaleciendo así la movilización de energías sociales en espacios de pequeña escala (municipios, localidades, microrregiones) que implementan cambios capaces de mejorar las oportunidades sociales, la viabilidad económica y las condiciones económicas de vida de la población. En este sentido, este documento tiene como objetivo reflexionar sobre tres casos de cooperativas en Brasil, con resultados positivos con respecto al desarrollo económico local. La investigación es cualitativa, y la investigación bibliográfica y documental es el método utilizado. Los resultados muestran que todas las cooperativas analizadas, a través de la gestión democrática y el trabajo en equipo, lograron crecer económicamente, generando empleos e ingresos y atrayendo inversiones y logros a su región, entre ellos, la construcción de escuelas comunitarias, el desarrollo de pequeñas empresas, mayores tasas de productividad de pequeños productores a través de la comercialización de insumos, entre otros. Dos de ellos se convirtieron en un punto de referencia en la producción y comercialización de sus materias primas, otro tuvo éxito al tener un comprador adecuado para su producto, que fracasó tan pronto como se cerró. Los resultados también muestran que el cooperativismo es una herramienta importante para el desarrollo social, económico y local, que tiene una gran importancia en la generación de empleos e ingresos y contribuye al desarrollo de la sociedad en su conjunto.

Palabras Clave: Cooperativas, Desarrollo Económico, Desarrollo Local. Trabajo en equipo.

\begin{abstract}
Cooperatives are characterized as organized groups of people who need capital underwriting to strengthen reserves and increase revenues and thus contribute to the emancipation of their members, thus a model of social organization based on the economic, social, and contributes to the generation and distribution of income, thereby strengthening the mobilization of social energies in small-scale spaces (municipalities, localities, microregions) that implement changes capable of enhancing social opportunities, economic viability and economic conditions of life of the population. In this sense, this paper aims to reflect on three cases of cooperatives in Brazil, with positive results regarding local economic development. The research is qualitative, and the bibliographic and documentary research is the method used. The results show that all the cooperatives analyzed, through democratic management and teamwork, managed to grow economically, generating jobs and income and attracting investments and achievements to their region, among them, the construction of community schools, development of small businesses, larger productivity rates of small producers through the marketing of inputs, among others. Two of them became a benchmark in the production and marketing of their raw materials, another succeeded while having a right buyer for their product, failing as soon as it closed. The results also show that cooperativism is an important tool for social, economic and local development, having great importance in generating jobs and income and contributing to the development of society as a whole.
\end{abstract}

Keywords: Cooperativism; Economic development; Local development; Team work 


\section{Introdução}

O cooperativismo é um modelo de organização social que desempenha um papel multidimensional de fundamental importância para o desenvolvimento local, uma vez que sustentado nos pilares, econômico, social, político e cultural, contribui para a geração e distribuição de renda, de forma justa e igualitária entre seus cooperados (SILVA, 2017).

Por cooperativas, entende-se que são agrupamentos de pessoas de forma organizada que necessitam de subscrição de capital para fortalecer as reservas e aumentar as receitas e assim contribuir para a emancipação dos seus cooperados. No entanto, na maioria das vezes, enfrentam dificuldades para se adequar a dinâmica competitiva imposta pelo mercado que leva estas organizações a "estabelecerem estratégias gerenciais a partir da aferição dos custos que são gerados no processo de produção e comercialização dos produtos" (FERREIRA e DAGNESE, 2014).

Baseado nessa organização coletiva de produção, distribuição e serviço, muitas cooperativas têm se tornado importantes ferramentas de desenvolvimento social, cultura, econômico, regional e comunitário (SCHALLENBERGER, 2003). Esse fato tem aumentado o grau de participação das cooperativas no desenvolvimento da economia dos países onde estas se encontram, gerando também qualidade de vida e desenvolvimento regional.

Segundo a organização das Cooperativas Brasileiras - OCB, o cooperativismo é um movimento, filosofia de vida e modelo socioeconômico capaz de unir desenvolvimento econômico e bem-estar social. Os conceitos que fortalecem sua identidade são: cooperação, transformação e equilíbrio (OCB, 2019).

Referente ao desenvolvimento que se faz menção neste trabalho, este não busca limitar-se somente ao campo social e econômico, mas busca abranger também os aspectos da região, isto é, desenvolvimento regional, local, etc. Moura e colaboradores (2002) destacam que o desenvolvimento local é um processo endógeno de mobilização das energias sociais em espaços de pequena escala (municípios, localidades, microrregiões) que implementam mudanças capazes de elevar as oportunidades sociais, a viabilidade econômica e as condições de vida da população.

Quanto ao desenvolvimento econômico local, concorda-se com as contribuições de Vitte (2006) quando afirma que este pode ser definido como o conjunto de estratégias e ações para a (re) construção da base produtiva local (para a ativação da economia local) e pode provocar impactos no território. Nesse sentido, o objetivo do presente artigo é refletir sobre 
três casos de cooperativas no Brasil com resultados positivos quanto ao desenvolvimento econômico local.

\section{Fundamentação Teórica}

Para se entender melhor o papel das experiências cooperativas e solidárias num processo de desenvolvimento sustentável, é necessário compreender primeiro o que significa o termo sustentabilidade. Segundo Schneider (2015, p. 102) "Sustentabilidade é um termo usado para definir ações e atividades humanas que visam suprir as necessidades atuais dos seres humanos, sem comprometer o futuro e o patrimônio das próximas gerações”. (...) É um termo que se relaciona diretamente com o "desenvolvimento econômico e material sem agredir o meio ambiente, usando os recursos naturais de forma inteligente para que eles se mantenham no futuro". A abrangência do significado exige, portanto, o planejamento estratégico de ações para a sua efetivação dentro de uma política de estado.

A Política Nacional de Desenvolvimento Regional (PNDR) tem como objetivo ativar os potenciais de desenvolvimento das regiões, explorando a diversidade em cada contexto e seus recursos e oferecendo à sociedade um caminho para elaboração e condução de projetos regionais de desenvolvimento, envolvendo federados, forças sociais e os setores produtivos.

De acordo com os objetivos da PNDR considera-se que a agricultura familiar tem papel preponderante pra efetivar o desenvolvimento de uma região, que segundo Dowbor (2010, p. 3) tem início a partir da organização local, com os meios disponíveis, realizando parcerias com instituições de pesquisa, formando cooperativas, criando novos canais conjuntos de comercialização. Esse mesmo autor considera que quando a população tem conhecimento do local onde eles se encontram e no qual trabalham o desenvolvimento se torna possível. Sabendo quais são suas origens, suas tradições culturais, suas capacidades econômicas, suas dificuldades ambientais, bem com, as diferenças de sua organização territorial e as desigualdades sociais.

Segundo Oliveira (2015), a aprendizagem sobre as realidades regionais mostra a importância do conhecimento dos diversos princípios culturais, não apenas sobre política e economia, indispensáveis para compreender o desenvolvimento. Percebe-se que o valor do conhecimento teórico e prático é tão abrangente, quanto indispensável para o desenvolvimento econômico sustentável de uma localidade ou de um país.

Nessa direção Terres (2017) descreve que a adoção de práticas mais sustentáveis e de diversificação do cultivo, com uso consciente do solo, possibilita a preservação do patrimônio genético das culturas, o consumo de alimentos da agricultura familiar e favorece a produção familiar, a partir do fato de que os mercados locais se tornam opções viáveis para o produtor 
rural.

Em junho de 2018 o Governo Federal divulgou o faturamento anual de U\$ 55 bi da agricultura familiar. No último Censo Agropecuário de 2017 consta que, “a agricultura familiar é a base da economia de 90\% dos municípios brasileiros com até 20 mil habitantes, sendo responsável pela renda de 40\% da população do País”. (IBGE, 2017).

O Ministério de Desenvolvimento Agrário (MDA) criou o Programa de Assistência Técnica e Extensão Rural "Mais Gestão" sendo considerada a primeira iniciativa governamental desenvolvida para pessoas jurídicas da agricultura familiar. O "Mais Gestão" é uma expressão instituída pelo MDA para designar um conjunto de ações de Assistência Técnica e Extensão Rural (ATER), direcionadas ao fortalecimento do cooperativismo da Agricultura familiar. Trata-se de uma metodologia que se baseia na oferta de serviços, ferramentas e consultorias para intervenção sistêmica e melhorias nas áreas de organização, gestão e comercialização.

Segundo Carvalho (2016) a prática cooperativista contribui para a educação das pessoas e ajuda a desenvolver uma mentalidade flexível, participativa, humana e solidária, cujos princípios são importantes na busca de qualidade de vida dos cooperados, de resultados econômicos e desenvolvimento social. As cooperativas se sustentam pela cooperação, e cooperar é agir de forma coletiva, é agir com os outros, é trabalhar de forma conjunta em prol de um mesmo objetivo.

Quanto à estrutura organizacional das cooperativas, Pinho (2012) diz que, quando as Cooperativas são bem estruturadas, auxiliam no estabelecimento de níveis de alçada e de decisão, visando alcançar objetivos estabelecidos em planejamentos estratégicos.

A Organização das Nações Unidas (ONU) elegeu o ano de 2012, como o ano do Cooperativismo, dedicando atenção especial ao tema e desenvolvendo através de suas agências o fomento a iniciativas relacionadas a esse modelo produtivo, que segundo a instituição, garante mais de 100 milhões de postos de trabalho no mundo e congregam 800 milhões de cooperados (ONU, 2011).

Segundo Carvalho (2016, p. 119)

A estrutura organizacional de uma Cooperativa é composta por órgãos formais e hierárquicos com as seguintes distribuições:

a) Assembleia Geral: composta por cooperados, poderá ser ordinária ou extraordinária. Representa o órgão supremo nas Cooperativas, com poderes dentro dos limites da Lei e do Estatuto social para as tomadas de quaisquer decisões, vincula todos os cooperados, ainda que ausentes ou discordantes; 
b) Conselho de Administração: a este Conselho compete planejar e traçar as normas para as operações da Cooperativa, controlar os resultados, respeitando os limites da lei e atendendo às recomendações da assembleia geral. Nele está inserida a Diretoria Executiva, a qual cumpre as determinações do Conselho de Administração, com auxílio de assessorias contratadas, da gerência e do quadro de colaboradores em suas áreas específicas: comunicação social, assessoria econômica, financeira e informática;

c) Conselho Fiscal: tem por competência a fiscalização de todas as atividades administrativas praticadas pelo conselho de administração. Esse Conselho é composto por seis membros (três efetivos e três suplentes) eleitos em Assembleia Geral para um mandato de um ano. Os Conselhos de Administração e Fiscal reúnem-se ordinariamente uma vez por mês e extraordinariamente sempre que necessário.

Considera-se que os órgãos formais que compõem a estrutura organizacional sejam indispensáveis para a existência de uma cooperativa. No entanto, segundo Bialoskorski (1997 apud CARVALHO 2016, p. 118-119) existem fatores que podem comprometer o modelo organizacional das Cooperativas, tais como: lentidão nas decisões, já que dependem do consenso entre os cooperados por meio de decisões colegiadas; a baixa profissionalização administrativa dos dirigentes; centralização, manifestada pela rotação no poder entre um grupo específico de associados; pouca participação dos associados nas assembleias e a falta de planejamento em longo prazo.

O sistema cooperativista no cenário internacional possui uma representação que é feita através da Aliança Cooperativa Internacional (ACI), fundada em 1895 e é considerado órgão máximo de representação das cooperativas no mundo. No Brasil é a Organização das Cooperativas do Brasil (OCB), a responsável por reunir as cooperativas em nível nacional, e que divide o cooperativismo em 13 ramos diferentes, a saber: Consumo; Crédito; Educacional; Especial; Infraestrutura; Habitacional; Produção; Mineral; Trabalho; Saúde; Turismo e Lazer; Transporte e Agropecuário (OCB, 2019). Porém neste trabalho foram estudadas somente três cooperativas representativas de desenvolvimento social, econômico, regional e local.

\section{Metodologia}

A pesquisa é do tipo qualitativa, sendo a investigação inteiramente bibliográfica e documental. Fonseca (2002, p.32) destaca que a pesquisa bibliográfica é feita a partir do levantamento de referências teóricas já analisadas, e publicadas por meios escritos e eletrônicos, como livros, artigos científicos, páginas de web sites. Qualquer trabalho científico 
inicia-se com uma pesquisa bibliográfica, que permite ao pesquisador conhecer o que já se estudou sobre o assunto.

$\mathrm{O}$ autor explica ainda que existem, as pesquisas científicas que se baseiam unicamente na pesquisa bibliográfica, procurando referências teóricas publicadas com o objetivo de recolher informações ou conhecimentos prévios sobre o problema a respeito do qual se procura a resposta.

Foram analisados três trabalhos sobre cooperativas voltadas ao desenvolvimento social e econômico (Tabela 1). Estes trabalhos foram selecionados pois se assemelham a proposta de reflexão que rege este trabalho.

Analisou-se nos textos as ações positivas adotadas pelas cooperativas em estudo que proporcionaram desenvolvimento social, econômico, regional e local.

Tabela 1. Relação de trabalhos selecionados para análise qualitativa

\begin{tabular}{|c|c|c|c|c|}
\hline $\mathbf{N}^{\mathbf{0}}$ & AUTOR & TÍTUTLO & LOCAL & ANO \\
\hline $\mathbf{1}$ & $\begin{array}{c}\text { Josivaldo Alves da } \\
\text { Silva }\end{array}$ & $\begin{array}{c}\text { O papel das cooperativas no desenvolvimento } \\
\text { econômico local: um estudo de caso na cooperativa } \\
\text { COOPERNORTE. }\end{array}$ & Goiás & 2017 \\
$\mathbf{2}$ & $\begin{array}{c}\text { Monica Mendes } \\
\text { Martins; } \\
\text { Claudia Souza } \\
\text { Passador }\end{array}$ & $\begin{array}{c}\text { O papel da organização cooperativa no } \\
\text { desenvolvimento de uma região: um estudo de caso } \\
\text { de uma cooperativa de pequenos produtores de São } \\
\text { Paulo }\end{array}$ & São Paulo & 2015 \\
$\mathbf{3}$ & $\begin{array}{c}\text { Gilvânia Nunes } \\
\text { Chaves }\end{array}$ & $\begin{array}{c}\text { Cooperativismo e desenvolvimento local: análise da } \\
\text { cooperativa agrícola dos produtores de mandioca de } \\
\text { São Felipe/BA }\end{array}$ & $\begin{array}{c}\text { São Felipe }- \\
\text { Bahia }\end{array}$ & 2010 \\
\hline
\end{tabular}

Fonte: Própria (2019)

A análise das informações consta nos resultados e discussão deste trabalho e visam servir de subsídio para novas reflexões acerca da temática, de modo a disseminar ideias e promover desenvolvimento.

\section{Resultados e Discussão}

A primeira cooperativa analisada é a COOPERNORT (A Cooperativa dos Produtores rurais do Norte Goiano Ltda.) fundada em 1979, com o objetivo de atender a uma demanda de serviços de secagem e armazenagens de grãos, tendo em vista que neste período havia uma grande deficiência de armazéns na região de Paraíso, norte do estado de Goiás. A partir de 1991, deu-se início a construção do laticínio, sendo inaugurado em 15 de setembro 1992.

Silva (2017) relata que a COOPERNORTE recebe diariamente um volume aproximado de 8 mil litros de leite, sendo que no período de seca reduz para 6 mil litros. A 
capacidade atual suporta a armazenagem de 30 mil litros de leite ao dia. Possui 445 associados e 22 colaboradores, que trabalham em regime de cooperação para a produção de leite pasteurizado tipo "C" queijo mussarela e manteiga de Leite.

O autor relata, ainda, que o mercado fornecedor da matéria prima para a COOPERNORTE, são os municípios de: Paraíso do Tocantins, Barrolândia, Miranorte, Miracema, Divinópolis, Marianópolis, Monte Santo, Chapada de Areia, Rosalândia, Fátima, Pugmil e Oliveira de Fátima, somando um total de 77 fornecedores de leite, sendo parte deles sócios da cooperativa, informações que constam também em seu manual do cooperado (COOPERNORTE, 2012).

Quanto a essa relação entre cooperativa e cooperado, Oliveira (2007) destaca que existe uma necessidade de as empresas cooperativas desenvolverem ações administrativas que alertem os cooperados da importância de os mesmos prestigiarem suas cooperativas, uma vez que, somente com o comprometimento dos cooperados as organizações do sistema cooperativo poderão se consolidar.

Souza (2017) explica que esta característica da gestão em buscar além de seus cooperados, fornecedores externos de seu produto, garante que a cooperativa sempre disponha seu produto para comercialização. Essa prática tem levado a COOPERNORTE a um estado de longevidade nos negócios e, isso pode estar relacionada a decisões conscientes de suas diretorias em relação à iniciativa de empreender por meio de boas práticas de inovação combinada com estratégia de mercado, a provisão de pessoas qualificadas e a gestão adequada de conflitos internos e externos.

Tais ações tendem a desenvolver não somente a cooperativa enquanto instituição, mas fortalece o cooperado, melhora sua condição de vida, permitindo-lhe qualidade de moradia e de vida, acesso ao esporte, cultua e lazer, além de promover desenvolvimento à toda a comunidade externa da cooperativa, gerando empregos e atraindo políticas públicas, melhorias e benfeitorias na sociedade (CENCI e FRANTZ, 2010).

A segunda cooperativa analisada foi a Cooperativa dos Produtores Agropecuários de São Pedro - SP (COOPAMSP), uma cooperativa composta apenas por "pequenos" produtores rurais, que utilizam somente mão-de-obra familiar em suas propriedades. Fundada por volta do final da década de 1980, ganhando forma através da assistência da LBA - Legião Brasileira de Assistência. No entanto, segundo aos autores do trabalho Martins e Passador (2009) foi somente a partir de 1988 através da presença dos assistentes técnicos da Escola Superior de Agricultura Luiz de Queiroz - ESALQ - USP que os primeiros produtores se 
organizaram e concretizaram a associação de produtores mutuários. Esses fatos culminaram na idealização e comercialização de leite.

A atuação em grupo possibilitou o recebimento de recursos e doações, além de contribuir para a vinda de benefícios para a comunidade, como a construção de uma escola municipal, em 1994, e a reativação de um posto de saúde. Com o desenvolver da atividade, em pouco tempo foi possível a construção de laticínio que passou a pasteurizar o leite de seus sócios e a comercializá-lo na forma de leite tipo C, o que garantiu ótimos valores de produção e rendimento. Atualmente o laticínio processa leite dos tipos B e C, produz iogurtes de vários sabores além de já possuir marca conhecida e respeitada na região, denominada "Leite do Campo" (MARTINS e PASSADOR, 2009).

O trabalho em equipe dentro das cooperativas é um fator essencial para que se consiga sucesso nas ações futuras. Kalleder (2012) enfatiza que a principal característica que define um trabalho em equipe é, sem dúvida, a existência de objetivos comuns, coletivos, a serem alcançados através do desempenho de todos os participantes. O esforço conjunto de todos os membros é indispensável para a consecução desses objetivos. Evidencia-se, portanto, que uma cooperativa que possui seus cooperados unidos e que compartilham dos mesmos objetivos, terá, certamente, maiores chances de consolidar-se num mercado cada vez mais competitivo.

Esses pontos positivos estimulam os cooperados a produzirem quantidades cada vez maiores e, consequentemente, receber maiores quantias de contribuição. Isto significa que os cooperados estão movimentando a economia local, comprando bens de serviços e acessando programas de esporte e lazer, além de melhorarem suas produções. Desse modo todos ganham: os cooperados, a cooperativa, os clientes da cooperativa e todos os que estão ligados a essa cadeia produtiva (PILETTI et al., 2015).

A terceira cooperativa analisada foi a Cooperativa Agrícola dos Produtores de Mandioca de São Felipe, com surgimento em 31 de março de1980, teve por objetivo estimular o desenvolvimento progressivo e a defesa de suas atividades sociais, econômicas e culturais de caráter comum, e a venda, em comum, da sua produção agrícola tanto no mercado nacional quanto internacional. A principal atividade desenvolvida pela COMASFE era, segundo Chaves (2010), a fabricação de farinha, sendo que a matéria-prima era comprada dos sócios e também de outros fornecedores, e chegou a produzir uma média de 500 sacos de farinha por semana. Vale ressaltar que quando a COMASFE iniciou suas atividades possuía um mercado consumidor certo - a Companhia Brasileira de Alimentos (COBAL), o que impulsionou significativamente sua expansão. 
Situação parecida também foi identificada por Sete et al. (2015) ao analisar a organização cooperativa sob a ótica dos cooperados da Cooperativa dos Granjeiros do Oeste de Minas Ltda - COGRAN, que está localizada no município de Pará de Minas/MG. Em suas verificações, os autores constataram que $50 \%$ dos cooperados entrevistados compram os insumos de que necessitam diretamente dos galpões da cooperativa e que a presença e o contato destes cooperados com sua cooperativa é constante, situação que segundo os autores, transmite confiança entre as partes e eleva a produtividade.

Chaves (2010) enfatiza que, segundo os dados levantados através de aplicação de questionários junto aos produtores, a Cooperativa Agrícola dos Produtores de Mandioca de São Felipe contribuiu para o desenvolvimento local, atuando tanto na dinâmica econômica do município, na geração de emprego e renda para mais de cem famílias, quanto no aspecto social, contribuindo com a valorização dos cooperados e moradores através da oferta de cursos de formação. Outro ponto diz respeito à gratificação por serviços prestados, aspecto que estimulava a participação. Enfatiza ainda que a cooperativa incentivou o surgimento de um elevado número de empregos.

Guardabassio et al. (2017, p.51) através de pesquisa exploratória realizada em duas cooperativas de reciclagem de Santo André (SP), corroboram com as informações acima quando relatam que uma das respostas comuns recebidas pelos cooperados ao serem indagados sobre o que a cooperativa representa para eles é: " Encontramos na cooperativa uma oportunidade de reinserção ao mercado de trabalho".

Uma outa questão importante a ser considerada na cooperativa COMASFE diz respeito a disponibilização de cursos de capacitação aos cooperados. A esse respeito Rossés et al. (2010) destacam que os programas de qualificação interna das cooperativas é um modelo muito utilizado nas grandes empesas e faz parte do planejamento estratégico que visa, entre outras coisas, a resolubilidade dos problemas em tempo mais curto, treinar e capacitar os cooperados para uso de tecnologias no espaço da cooperativa e assim atualizar o modelo de produção, minimizar os afazeres e industrializar os sistemas de produção.

Chaves (2010) explica que com o lucro da cooperativa os associados chegaram a comprar 120 tarefas de terra a fim de que todos tivessem seu espaço para plantar. Também conseguiram instalar dentro da cooperativa uma farmácia e um mini supermercado, com o intuito de que os cooperados tivessem acesso a produtos alimentícios e remédios a preços mais acessíveis. Porém, quando a companhia que comprava toda a farinha produzida, a COBAL, foi extinta, a cooperativa começou a declinar e há oito anos suas atividades se 
encontram paralisadas. A ausência de mercado consumidor foi o fator mais decisivo para o declínio da cooperativa, mas não o único.

Evidencia-se, portanto, que o planejamento e a gestão eficiente devem ser pontos sempre em evidencia nas reuniões das cooperativas, uma vez que estes podem ser fatores limitantes na atividade da organização, mesmo que as ações de produção e comercialização estejam aparentemente satisfatórias, conforme defendem Freitas et al. (2011). Nesse contexto, ressalta-se ainda as contribuições de Rodrigues (2008), quando defende que as possibilidades do desenvolvimento do cooperativismo e a qualidade de seu desempenho como movimento econômico e social dependem de seus líderes e participantes para que articulem a visão de um mundo melhor.

Desse modo, a cooperativa tem seu sucesso atrelado ao trabalho coletivo e responsável tanto de seus líderes quanto de seus cooperados. O sucesso de um é o sucesso de todos.

\section{Conclusões}

O cooperativismo, é um modelo de organização social que desempenha um papel de fundamental importância para o desenvolvimento local, uma vez que contribui para a geração e distribuição de renda, de forma justa e igualitária entre seus cooperados, trazendo benefícios para toda a sociedade.

Os exemplos de cooperativas aqui retratadas demonstraram que é possível gerar emprego e renda, promover desenvolvimento regional e local e atrair políticas públicas, uma vez que o trabalho desenvolvido seja pautado nos princípios de cooperação e trabalho em equipe, sempre regidos por uma liderança coletiva e ética.

Diversos outros exemplos de cooperativas podem ser usados para exemplificar as vantagens desse sistema para o desenvolvimento social, econômico, cultural, regional e local, de modo que possam ser usados de modelo para as demais cooperativas, ampliando assim as possibilidades de desenvolvimento pelo país.

Esta pesquisa analisa apenas alguns casos, no entanto, o campo de atuação do cooperativismo é bastante amplo no que diz respeito ao desenvolvimento econômico local, o que abre o leque para novas propostas de investigação.

\section{Referências}

BRASIL (2019). Política nacional de desenvolvimento regional. Ministério da Integração Nacional. Disponível em: <http://www.mi.gov.br/politica-nacional-de-desenvolvimentoregional-pndr>. Acesso em: 29 de julho. 2019. 
CENCI, A. R.; FRANTZ, W. Desenvolvimento, cooperativismo e a constituição federal de 1988. Constituição, Economia e Desenvolvimento. Revista da Academia Brasileira de Direito Constitucional. Curitiba, 2010, n. 3, Ago-Dez. p. 124-141. Disponível em: http://www.abdconst.com.br/revista4/cenci.pdf. Acesso em 24 de junho de 2019.

CARVALHO, Adriano Dias de. Estratégias de marketing relacional em cooperativas de crédito: um estudo no estado de minas gerais. Piracicaba, 2016. 201 folhas. Tese (Doutorado em Administração) - Faculdade de Gestão e Negócios da Universidade Metodista de Piracicaba, 2016.

CHAVES, Gilvânia Nunes. Cooperativismo e desenvolvimento local: análise da cooperativa agrícola dos produtores de mandioca de São Felipe. 2010. 173 folhas. Dissertação (mestrado) - Universidade do Estado da Bahia, Programa de pós-graduação em Cultura Memória e Desenvolvimento Regional, 2010.

COOPERNORT - Cooperativa Agropecuária Tocantinense, COOPERNORTE. Manual do Cooperado. Palmas - TO, SESCOOP/TO, 2012, 48, p.

DOWBOR, L. Desenvolvimento local e a racionalidade econômica. 2006, 4p. Disponível em: http://dowbor.org/2006/10/desenvolvimento-local-e-racionalidade-economica-doc.html/ Acesso em: 29 julho 2019.

FERREIRA, Gabriel Murad Velloso; DAGNESE, Felipe. Constituição e desenvolvimento de cooperativas. Santa Maria: Universidade Federal de Santa Maria, Colégio Politécnico; Rede e-Tec Brasil, 2014.

FONSECA, J. J. S. Metodologia da pesquisa científica. Fortaleza: UEC, 2002.

FREITAS, A. F de.; FREITA, A. F de.; PEDRA, M. de Sá. Participação na gestão de cooperativas: a estratégia de organização do quadro social (oqs). Em Extensão, Uberlândia, v. 10, n. 1, p. 90-99, jan. / jun. 2011. Disponível em: www.seer.ufu.br/index.php/revextensao/article/download/20648/10990. Acesso em 24 de junho de 2019.

GUARDABASSIO Eliana Vileide; PEREIRA, Raquel da Silva; AMORIM, Wilson Aparecido Costa de. Geração de trabalho e renda por meio do cooperativismo. Revista de Gestão Ambiental e Sustentabilidade - GeAS, Vol. 6, N. 1. Janeiro. / Abril. 2017. Disponível em: http://www.revistageas.org.br/ojs/index.php/geas/article/ view/418/pdf. Acesso em 24 de junho de 2019.

IBGE - INSTITUTO BRASILEIRO DE GEOGRAFIA E ESTATÍSTICA. Censo Agropecuário 2017. Censo agropecuário, Rio de Janeiro, v. 7, p.1-108, 2017. Disponível em: https://censoagro2017.ibge.gov.br/ Acesso em 29 de julho de 2019.

KALLEDER, Haroldo. A importância do trabalho em equipe no ambiente cooperativo. FABE em Revista, Bertioga, v.3, n.3, ago/out. 2012. Disponível em: http://fabeemrevista.com.br/3/02.pdf. Acesso em 24 de junho de 2019.

MARTINS, M. M.; PASSADOR, C. S. O papel da organização cooperativa no 
desenvolvimento de uma região: um estudo de caso de uma cooperativa de pequenos produtores de São Paulo. In: Anais do $47^{\circ}$ Congresso da Sociedade Brasileira de Economia, Administração e Sociologia Rural - Porto Alegre, 26 a 30 de julho de 2009.

MOURA, Maria Suzana et al. Desenvolvimento Local Sustentável: O que sinalizam as práticas. Reunião ANPED 2002. Disponível em: http://www.anpad.org.br/admin/pdf/enanpad2002-pop-1546.pdf. Acesso em 24 de junho de 2019.

OCB - SINDICATO E ORGANIZAÇÃO DAS COOPERATIVAS BRASILEIRAS. O que é cooperativismo. Disponível em: https://www.ocb.org.br/o-que-e-cooperativismo. Acesso em 24 de junho de 2019.

OLIVEIRA, J. R de. O comprometimento do cooperado com a cooperativa. 2007. 102 folhas. Dissertação (Mestrado) - Universidade Federal de Santa Maria, Programa de Pós-graduação em Engenharia de Produção. Santa Maria - RS, 2007.

OLIVEIRA, A.E.A. Marxismo e questão regional. Lutas Sociais, São Paulo, vol.19 n.35, p.112-128, jul./dez. 2015. Disponível em: https://revistas.pucsp.br/index.php/ls/article/view/26682/pdf. Acesso em: 07 jun. 2019.

\section{ONU - ORGANIZAÇÃO DAS NAÇÕES UNIDAS. Agências da ONU lançam Ano Internacional das Cooperativas 2012. 2011. Disponível em:} $<$ https://nacoesunidas.org/agencias-da-onu-lancam-ano-internacional-das-cooperativas2012/>. Acesso em: 12 jul. 2019.

PILETTI, D.; BORGES, G. R.; BARROS, I. C. R. Os princípios do cooperativismo e o trabalho em equipe em cooperativas de Garibaldi-RS. NAVUS, Florianópolis - SC, v. 5, n. 4, p. 34-45, out./dez, 2015. Disponível em: http://navus.sc.senac.br/index.php/navus/article/download/265/260. Acesso em 24 de junho de 2019.

PINHO, C. M. D. Análise das redes de localidades Ribeirinhas Amazônicas no tecido urbano estendido: uma contribuição metodológica. Dissertação (Mestrado) - Instituto Nacional de Pesquisas Espaciais. São José dos Campos, 2012.

RODRIGUES, Roberto. Cooperativismo - democracia e paz: surfando a segunda onda. São Paulo: OCB, 2008.

ROSSÉS et al. Sistema de gestão em Cooperativas: o caso da Cooperativa Agropecuária Júlio de Castilhos. In: Anais do VII Simpósio de excelência em gestão e tecnologia, 2010.

SCHALLENBERGER, Erneldo. Cooperativismo e desenvolvimento comunitário. Revista Mediações, Londrina, v.8, n.2, p. 9-26. Jul./dez, 2003.

SCHNEIDER, José Odelso. Cooperativismo e desenvolvimento sustentável. Otra Economía, vol. 9, n. 16, enero-junio, 2015.

SETTE, Ana Tarsila de Miranda e Souza et al. A organização cooperativa sob a ótica dos cooperados. In: XLIII CONGRESSO DA SOBER "Instituições, Eficiência, Gestão e 
Contratos no Sistema Agroindustrial", Anais eletrônico, Ribeirão Preto, 24 a 27 de Julho de 2005 Sociedade Brasileira de Economia e Sociologia Rural. Disponível em: http://www.sober.org.br/palestra/2/952.pdf. Acesso em junho de 2019.

SILVA, Josivaldo Alves da. O papel das cooperativas no desenvolvimento econômico local: um estudo de caso na cooperativa COOPERNORTE. Revista Desafios - v. 04, n. 04, 2017. DOI: http://dx.doi.org/10.20873/uft.2359-3652.2017v4n4p51.

TERRES, J. O sol brilha para todos: A realidade da agricultura familiar em Guarapuava. Central Cultura de comunicação, Guarapuava, 2018.

VITTE, Claudete de Castro Silva. Gestão do desenvolvimento econômico local: algumas considerações. Revista Internacional de Desenvolvimento Local. Vol. 8, N. 13, p. 77-87, Set. 2006. 